\title{
PERSPECTIVES OF MEDICAL STUDENTS \& TEACHERS REGARDING THE USE OF DIFFERENT LECTURE METHODS
}

\author{
Pritish Krishna Raut ${ }^{1}$, Sachin Gupta ${ }^{2}$ \\ ${ }^{1}$ Associate Professor, ${ }^{2}$ Assistant Professor, Dept. of Community Medicine, \\ DVVPF's Medical College, Ahmednagar, Maharashtra, India.
}

\section{ABSTRACT}

Background: Teaching methods used for lectures are mostly teacher-centered a nd not learner-centered. The method used for lectures is mainly determined by the teacher as per his/her convenience. The students are never asked about the lecture method which helps them in better learning. This can lead to poor understanding by students which in turn may hamper the learning process. Objectives: To find out the perspectives of students $\&$ teachers about the use of different lecture methods. Methodology: Views \& opinions of 488 medical students \& 47 medical teachers of a medical college about different types of teaching methods namely Traditional (chalk and board), over head projector and power point presentation were collected in an observational study with the help of separate questionnaires. Results: Most of the students (51.6\%) prefer traditional method for the lectures, $54.9 \%$ have better understanding with traditional method $(p<0.05), 61.5 \%$ students feel that they can concentrate more with traditional method $(p<0.05)$ while $58 \%$ students feel that it is easy to note down important points with the help of Power point presentation $(p<0.05)$. Large proportion of teachers $(78.7 \%)$ prefer Power point presentation for classroom teaching, $76.6 \%$ teachers are willing to change to other method of classroom teaching if required, $80.5 \%$ teachers would like to have their performance monitored for self evaluation \& self improvement. Overhead projector is neither preferred by students nor teacher as a teaching tool. Conclusion: A combination of traditional and power point presentation is preferred by the students for a better teaching-learning process.

KEYWORDS: Lecture; Chalk and talk; Powerpoint.

\section{INTRODUCTION}

Didactic lecture for a large group is one of the oldest teaching-learning method. Lectures are an efficient means of transferring knowledge and concepts to large groups. They can be used to stimulate interest, explain concepts, provide core knowledge, and direct student learning. A lot of changes have occurred in this teaching-learning method during the past $15-20$ years. From chalk and talk to more advanced powepoint methods, teachers are using different methods for delivering lectures. Every teaching method has its merits and demerits[1], hence it is difficult to decide which method is superior than the other one.

Commonly used techniques in lecture theatre are traditional chalk \& talk, Power Point Presentation (PPT) and overhead projector with transparencies (OHP). Many

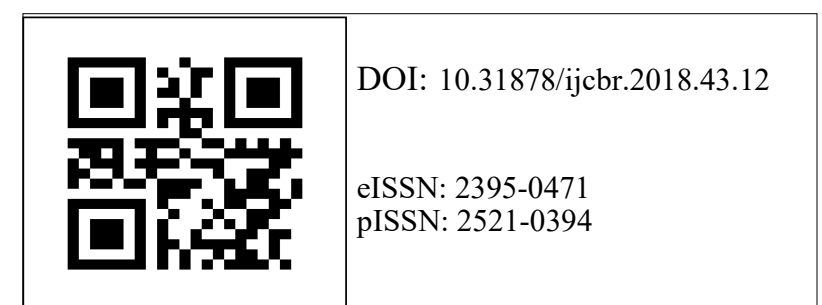

studies have compared the effectiveness of traditional method versus PPT. During some comparative studies, the students taught by traditional chalk \& talk method performed better than those taught by using PPT [2,3]. While some other studies suggest that use of PPT is preferred by the students because of certain advantages $[4,5]$. But, even though there is preference given to one method either by the teachers or students, it is found that combination of more than one method is always better for understanding, as suggested by some studies $[6,7]$.

Most of the teaching methods used for lectures are teacher-centered and not learner-centered[8]. The method used for lectures is mainly determined by the teacher as per his/her convenience. Though the effectiveness depends on the teacher on how appropriately the aid is being used $[9,10]$. The students are never asked about the lecture method which helps them in better learning. This can lead to poor understanding by students which in turn may hamper the learning process.

Hence, an attempt is made to find out the gap in perspectives of medical students $\&$ teachers regarding the

Correspondence: Sachin Gupta, Assistant Professor, Dept. of Community Medicine, DVVPF's Medical College, Ahmednagar, Maharashtra, India. Email: callsachingupta@gmail.com 
use of lecture method for classroom teaching.

\section{MATERIALS AND METHODS}

Study design: Observational type of study

Study participants: Students \& teachers of Medical College.

Study tool: Questionnaire

Study Procedure: A separate questionnaire was prepared for students and teachers consisting of questions to find out their perspectives regarding the use of teaching methods in the classroom. This questionnaire was administered to all MBBS students and faculty members of the institution and responses were collected from those who were willing. Also, they were asked not to reveal their identity while filling the questionnaire to get the authentic responses.

Study sample: A total of $\mathbf{4 8 8}$ medical students and $\mathbf{4 7}$ faculty members voluntarily submitted their responses.

Data analysis: Data was compiled and analysed with the help of softwares Microsoft office Excel, SPSS version 16.0 and OpenEpi version 2.3.1.

\section{RESULTS}

Out of 488 medical students, 146 (29.9\%) were from First MBBS, 121 (24.8\%) from Second MBBS, 142 (29.1\%) from Third MBBS \& 79 (16.2\%) from Final MBBS course. Most of the students (51.6\%) prefer traditional method for the lectures, $54.9 \%$ have better understanding with traditional method $(p<0.05), 61.5 \%$ students feel that they can concentrate more with traditional method $(p<0.05)$ while $58 \%$ students feel that it is easy to note down important points with the help of Power point presentation $(p<0.05)$.

There was not much of a difference between chalk and talk and PPT presentation when it comes to memorizing the topic ( $p>0.05)$. Majority of the students $(55.1 \%)$ will prefer using traditional chalk and talk method if they become teacher $(p<0.05)$.

Students feel that traditional method is more interactive but it is time consuming, slow method and also there is visibility problem. OHP is also having visibility and handwriting issues and its boring. PPT presentations are too fast but they are good for showing pictures, diagrams, animations, videos, etc.

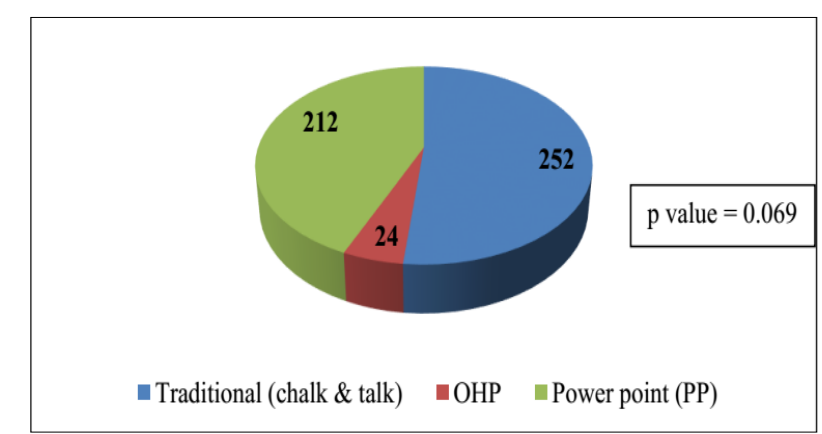

Fig 1a: Method to be used by teacher during classroom teaching

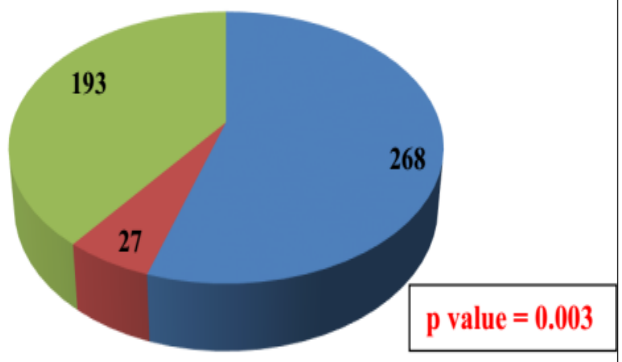

-Traditional (chalk \& talk) $\quad$ OHP $\quad$ Power point (PP)

Fig1b: Better understanding of topic

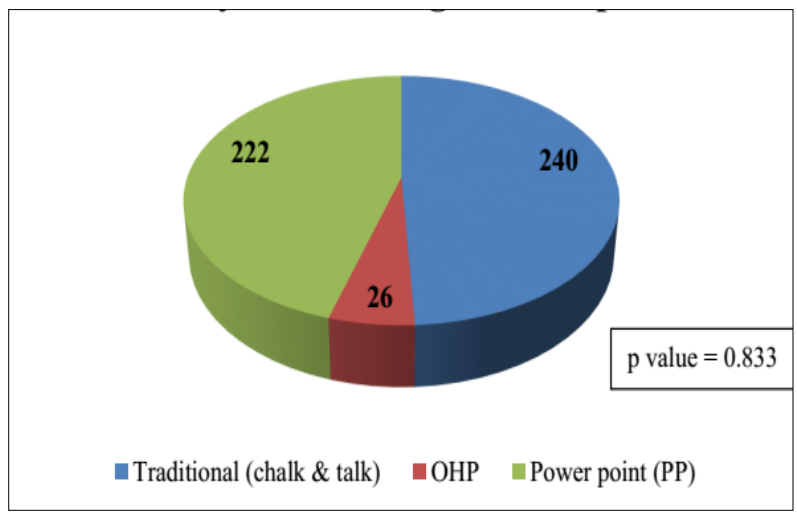

Fig 1c: Memorizing of the topic

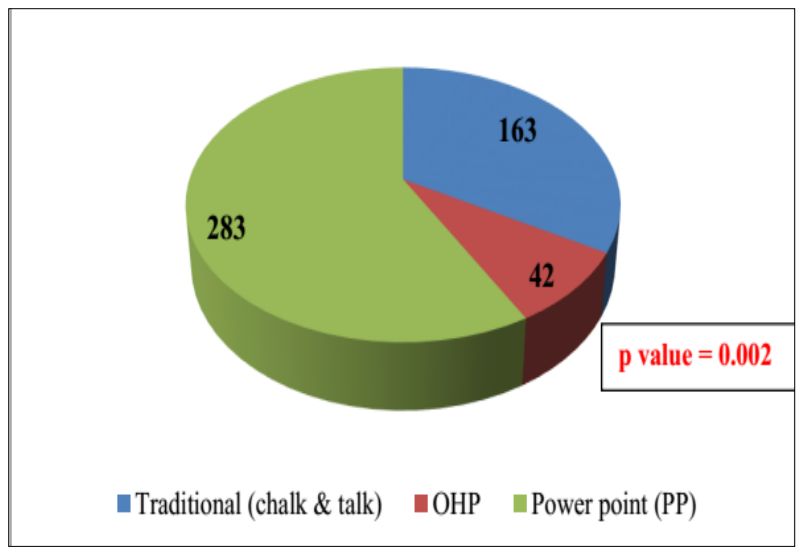

Fig 1d: Easy to note down important points

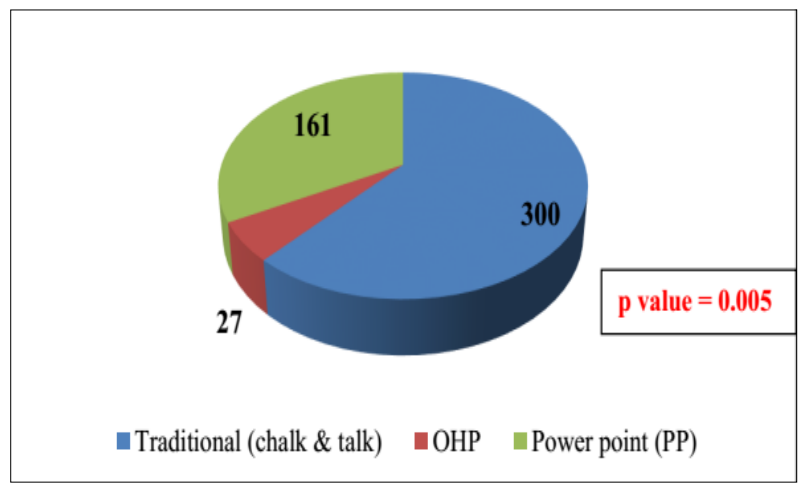

Fig 1e: More concentration $\&$ less distraction 


\section{Makes classmates more attentive $\&$ less disturbing to you}

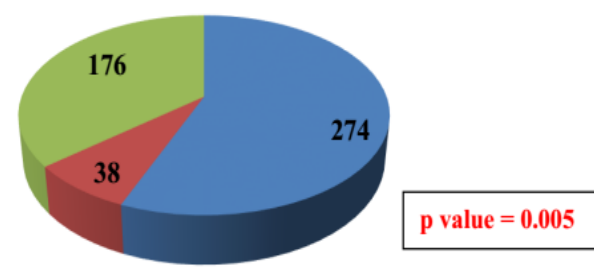

- Traditional (chalk \& talk) $\quad$ OHP $\quad$ - Power point (PP)

Fig $1 f$

\section{Makes teacher more comfortable during teaching}

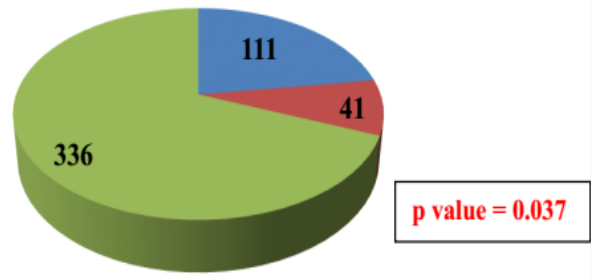

- Traditional (chalk \& talk) $\quad$ OHP $\quad$ - Power point (PP)

Fig 1g

\section{If you become teacher, method you would like to use}

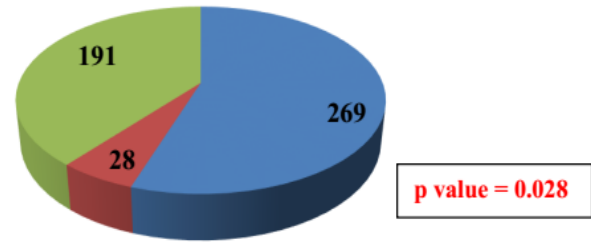

Traditional (chalk \& talk) $\quad$ OHP $\quad$ O Power point (PP)

Fig1h: If you become teacher, method you would be use

Figure 1: Responses of students about different lecture methods.

Analysis of the questionnaire administered to medical teachers reveals following findings:

Total 47 medical teachers participated in the study.

Out of 47,34 (72.3\%) teachers were from pre or paraclinical subjects while $13(27.7 \%)$ teachers were from clinical subjects. 13 (27.7\%) were Professors, 8 (17\%) were Asso. Professors and 26 (55.3\%) were Assistant Professors.

Out of 47 teachers, 37 (78.7\%) teachers prefer PP for classroom teaching; while 7 (14.9\%) teachers prefer traditional method and only $3(6.4 \%)$ teachers prefer $\mathrm{OHP}$.
Most common reasons for using the preferred method by teachers being they feel that student understanding is better and they are comfortable with the use of that particular method.

$36(76.6 \%)$ teachers agreed that they will change to other method of classroom teaching if required.

$43(91.5 \%)$ teachers take the review of their lecture

$38(80.5 \%)$ teachers like to have their performance being monitored for self-evaluation \& self-improvement.

Overhead projector is neither preferred by students nor teacher as a teaching tool.

\section{DISCUSSION}

Being a large group teaching method, a didactic lecture is bound to have its own advantages and disadvantages. There are different audio-visual aids available to facilitate the teaching-learning process by this method. Traditional chalk and talk method is preferred by many students. This method helps them in better understanding of the topic (54.9\%), in more concentration and less distraction (61.5\%) and making classmates more attentive and less disturbing to them (56.1\%). These findings were consistent with one previous study10. This fact is also proved when comparative studies are undertaken and ability to answer questions among students is tested2,3. But at the same time students who participated in our study also feel that for certain advantages PPT presentation should also be used during lecture method, like PPT presentation helps them in taking down notes easily (58.0\%) and also feels that teacher is more comfortable while using PPT presentation. Similar kind of findings were observed in a study, where students prefer chalk and talk method but PPT is useful in taking down notes[11]. Though there are studies which clearly states the preference of PPT presentation during lectures[4,5].

As students have mentioned about the advantages of both the methods; findings were supported by few studies where combination of multiple methods is found useful[6,7].

We also asked teachers about their perspectives about the use of different aids during lectures. Most of the teachers nowadays prefer using PPT presentation (78.7\%), mostly because they are comfortable with that method and they also feel that the students' understanding is better with this method. A previous study showed that teachers prefer to use chalk and talk and PPT presentations during the lecture[8]. Most of the teachers take review of the lecture. Almost $76.6 \%$ teachers agreed that they will change to other method of classroom teaching if required while $80.5 \%$ of teachers would like to have their performance being monitored for self-evaluation \& self-improvement. 


\section{CONCLUSION}

Results suggested that the traditional method is the one which is favoured by many medical students along while the power point presentations are more useful for noting down the important points; while many teachers prefer using power point presentations for classroom teaching. Further, sensitization of the teachers regarding the optimum use of power point presentations and giving more emphasis on use of traditional methods can be done, and outcomes based on the improvement in the performance of the students will be assessed later.

\section{REFERENCES}

1. Jadhav V. S. Adchitre S.A. Magare A.R. Surve R. R. \& Mahajan S. M: A Comparative Study Of Blackboard Teaching With Powerpoint Teaching In Third Year Medical Students.: International Journal of current Medical and Applied sciences; 2016, 11(1),17-21 .

2. S. Waheeda, K. Sathiya Murthy: A Comparative Study of blackboard teaching with Powerpoint teaching in 1 year medical students, National Journal of Basic Medical Sciences; 2015, 6(1), 11-13.

3. deSa SB, Keny MS. PowerPoint versus Chalkboard Based Lectures in Pharmacology: Evaluation of Their Impact on Medical Student's Knowledge and Their Preferences. Int J Adv Health Sci 2014; 1(5): 10-14.

4. Ramachandrudu RVSNS. Powerpoint presentation vs blackboard teaching: a comparative study and evaluation in Government Medical College, Ananthapuramu, Andhra Pradesh for II M.B.B.S students: a questionnaire based study. J. Evolution Med. Dent. Sci. 2016;5(26):1352-1356, DOI: 10.14260/ jemds/2016/319

5. Nusrat Jabeen, Abdul Ghani. "Comparison of the traditional Chalk and Board Lecture System Versus Power Point Presentation as a Teaching Technique for teaching Gross Anatomy to the First Professional Medical Students". Journal of Evolution of Medical and Dental Sciences 2015; Vol. 4, Issue 11, February 05; Page: 1811-1817, DOI: 10.14260/ jemds/2015/258

6. Sultan Ayoub Meo, Shaikh Shahabuddin, Abeer A. Al Masri, Shaikh Mujeeb Ahmed, Mansoor Aqil, Muhammad Akmal Anwer and Abdul Majeed Al-Drees: Comparison of the Impact of PowerPoint and Chalkboard in Undergraduate Medical Teaching: An Evidence Based Study: Journal of the College of Physicians and Surgeons Pakistan 2013, Vol. 23 (1): 47-50

7. Petimani MS, Adake P. Blackboard versus PowerPoint presentation: Students opinion in medical education. Int J Educ Psychol Res 2015;1:289-92
8. P. Aranha, D. Shettigar, S. Varghese: Chalk and Talk Versus Powerpoint - Perception of Nursing Faculty in India: American International Journal of Research in Humanities, Arts and Social Sciences, 3(2), JuneAugust, 2013, pp. 264-267

9. Dr. Hitesh Mishra, Dr. Vipin Kumar, Dr. Pankaj Kumar Modi: Comparison of Different Teaching Methodologies in a Medical College in North India: Indian Journal of Basic \& Applied Medical Research; March 2013: Issue-6, Vol.-2, P. 464-469

10. Ethel L. B. Novelli, Ana AngeLica H. Fernandes: Students Preferred Teaching Techniques for Biochemistry in Biomedicine and Medicine Courses: BIOCHEMISTRY AND MOLECULAR BIOLOGY EDUCATION Vol. 35, No. 4, pp. 263-266, 2007

11. Saritha Gadicherla and Ramesh Babu M: Comparison of Blackboard and Powerpoint Presentation in Teaching Biochemistry for MBBS Students: International Journal of Biomedical and Advance Research 2018; 9(1): 19-22.

How to Cite this article: Pritish Krishna Raut, Sachin Gupta. Perspectives of Medical Students and Teachers Regarding the Use of Different Lecture Methods. Int. j. clin. biomed. res. 2018;4(3): 57-60. 